\title{
INDICADORES MICROBIOLÓGICOS DE SOLO EM PASTAGEM COM APLICAÇÃO SUCESSIVA DE DEJETOS DE SUÍNOS
}

\author{
Danni Maisa da Silva ${ }^{(1)^{*}}$, Zaida Inês Antoniolli( ${ }^{(2)}$, Rodrigo Josemar Seminoti Jacques ${ }^{(2)}$, \\ Andressa de Oliveira Silveira ${ }^{(3)}$, Diego Armando Amaro da Silva ${ }^{(4)}$, Magnus Maurício \\ Rache $^{(1)}$, Vitor Hugo Gomes Passos ${ }^{(1)}$ e Bruno Rafael da Silva ${ }^{(1)}$
}

(1) Universidade Estadual do Rio Grande do Sul, Unidade Três Passos, Três Passos, Rio Grande do Sul, Brasil.

(2) Universidade Federal de Santa Maria, Departamento de Solos, Santa Maria, Rio Grande do Sul, Brasil.

(3) Universidade Federal de Santa Maria, Departamento de Engenharia Sanitária e Ambiental, Santa Maria, Rio Grande do Sul, Brasil.

(4) Universidade Federal de Santa Maria, Campus de Frederico Westphalen, Departamento de Ciências Agronômicas e Ambientais, Programa de Pós-graduação em Agronomia - Agricultura e Ambiente, Frederico Westphalen, Rio Grande do Sul, Brasil.

* Autor correspondente.

E-mail: danni.maisa@bol.com.br

\section{RESUMO}

O uso de dejetos líquidos de suínos como fertilizante do solo é uma prática comum na Região Sul do Brasil. Apesar de ter benefícios na reutilização dos dejetos, essa prática apresenta sérios riscos ambientais. Os indicadores microbiológicos de qualidade do solo são bastante sensíveis e permitem o monitoramento das condições do ambiente edáfico. Objetivou-se avaliar a qualidade microbiológica do solo de pastagens com diferentes históricos de uso sucessivo de dejetos líquidos de suínos. Determinaram-se o teor de $\mathrm{C}$ da biomassa microbiana, a respiração microbiana do solo, o quociente metabólico $\left(q \mathrm{CO}_{2}\right)$ e a atividade das enzimas $\beta$-glicosidase, urease e hidrólise do diacetato de fluoresceína (FDA), em áreas de pastagem com uso de dejetos de suínos há dois anos (A2) e 14 anos (A14) e em área com mata nativa (MN). O uso sucessivo de dejetos de suínos em pastagem não influenciou o $\mathrm{C}$ da biomassa e a respiração microbiana do solo, que variaram conforme a época de coleta. $\mathrm{O} q \mathrm{CO}_{2}$ não foi influenciado pelo uso de dejetos de suínos no solo; a atividade enzimática do solo foi influenciada pelo uso de dejetos de suínos, sendo que a urease e a FDA foram sensíveis na detecção de diferenças na atividade dos solos com uso de dejetos de suínos, enquanto a $\beta$-glicosidase não permitiu a diferenciação entre as áreas estudadas.

Palavras-chave: qualidade do solo, carbono, biomassa, respiração, atividade enzimática. 


\title{
ABSTRACT: MICROBIOLOGICAL INDICATORS OF PASTURE SOIL WITH SUCCESSIVE APPLICATIONS OF PIG SLURRY
}

\begin{abstract}
Pig slurry use as soil fertilizer is a common practice in southern Brazil. In spite of the benefits of reusing waste, this practice poses serious environmental risks. Microbiological indicators of soil quality are very sensitive and allow soil environment conditions to be monitored. The aim of this study was to evaluate the microbiological quality of pasture soils with different histories of successive use of pig slurry. Determinations were made of $C$ content in the microbial biomass, soil microbial respiration, metabolic quotient $\left(q \mathrm{CO}_{2}\right)$, activity of the enzymes $\beta$-glycosidase and urease, and fluorescein diacetate (FDA) hydrolysis in grazing areas under the use of pig slurry for two (A2) and 14 years (A14) and in a native forest (NF) area. The successive use of pig slurry on pasture did not affect C biomass and soil microbial respiration, which varied according to the time of collection. The $q \mathrm{CO}_{2}$ was not affected by the use of pig slurry in the soil. Soil enzymatic activity was affected by the use of pig slurry; urease and FDA were sensitive in detecting differences in soil activity with the use of pig slurry, whereas the $\beta$-glycosidase enzyme did not allow differentiation among the areas studied.
\end{abstract}

Keywords: soil quality, carbon, biomass, respiration, enzymatic activity.

\section{INTRODUCÃO}

O Brasil produz aproximadamente 39 milhões de suínos por ano em sistema de confinamento de animais, ocasionando o acúmulo, em pequenas áreas, de grandes volumes de dejetos na forma líquida, que normalmente são aplicados no solo como fonte de nutrientes às culturas agrícolas (Giacomini et al., 2014). Em muitos casos, essa é uma das principais formas de fertilização das pastagens destinadas à bovinocultura de leite, uma vez que ambas as atividades ocorrem conjuntamente nessas propriedades rurais do sul do Brasil.

Embora sejam evidentes os benefícios da reutilização dos dejetos de suínos para fertilização das áreas na própria unidade geradora, muitas vezes a elevada quantidade que é aplicada nas mesmas áreas, por longos anos, pode exceder a capacidade de suporte dos solos (Girotto et al., 2010). Com isso, podem ocorrer a adição de coliformes totais (Sá et al., 2014) e o acúmulo nos solos de $\mathrm{Cu}, \mathrm{Zn}$ e Mn (Basso et al., 2012), P e K (Scherer et al., 2010), além de $\mathrm{N}$, com riscos de lixiviação e contaminação das águas superficiais e subsuperficiais (Hernández et al., 2013), que podem ocasionar sérios problemas de contaminação ambiental. Por isso, em sistemas tão intensivos como esses, o monitoramento permanente da qualidade dos solos é um processo fundamental à sustentabilidade da atividade agrícola.

Os indicadores de qualidade microbiológica do solo são bastante sensíveis (Kaschuk et al., 2011) e a utilização deles pode indicar problemas ou melhorias no ambiente edáfico, previamente aos indicadores físicos e químicos em razão das práticas, como a aplicação sucessiva de dejeto líquido de suínos, possibilitando a escolha do melhor sistema de manejo do solo e permitindo a viabilidade econômica e ambiental da atividade agropecuária.

Dentre os principais indicadores microbiológicos utilizados para avaliar a qualidade do solo, destacam-se a determinação do C da biomassa, respiração microbiana e atividade enzimática do solo (Araújo et al., 2012; Kheyrodin et al., 2012; Balota et al., 2014). A biomassa microbiana é um indicador sensível a mudanças no ecossistema, pois representa o destino inicial do $\mathrm{C}$ em transformação, e é uma das principais fontes de produção do $\mathrm{CO}_{2}$ e das enzimas do solo (Moreira e Siqueira, 2006). Estudos apontam que o uso de dejetos de suínos pode incrementar o $\mathrm{C}$ da biomassa e a respiração basal do solo (Couto et al., 2013), além de influenciar a atividade enzimática, apresentando diferentes tendências conforme a enzima estudada (Balota et al., 2011).

Considerando-se que, em áreas com uso sucessivo de dejetos de suínos, pouco se conhece sobre o comportamento e a sensibilidade desses bioindicadores de qualidade do solo, levantou-se a hipótese de que, nestas condições, em função do dejeto elevar os teores de nutrientes do solo (Giacomini et al., 2014), ocorre o aumento da atividade e da densidade dos microrganismos do solo, entretanto, o acúmulo de Cu e Zn (Basso et al., 2012), causa a redução na diversidade dos bioindicadores do solo. Assim, objetivou-se avaliar a qualidade 
microbiológica do solo de pastagens com diferentes históricos de uso sucessivo de dejetos líquidos de suínos, utilizando para isso os indicadores teor de $\mathrm{C}$ da biomassa microbiana, respiração microbiana do solo, quociente metabólico $\left(q \mathrm{CO}_{2}\right)$ e atividade enzimática.

\section{MATERIAL E MÉTODOS}

Este trabalho foi realizado na localidade de Erval Novo, no município de Três Passos, RS $\left(53^{\circ} 56^{\prime} \mathrm{W}\right.$ e $\left.27^{\circ} 30^{\prime} \mathrm{S}\right)$, em uma propriedade rural produtora de suínos, leite e grãos, que apresenta as características de relevo ondulado, altitude média de $413 \mathrm{~m}$, clima do tipo Cfa, com temperatura média anual em torno de $19{ }^{\circ} \mathrm{C}$ e precipitação pluvial entre 1.800 e $2.000 \mathrm{~mm}$, bem distribuídos ao longo do ano (Silva et al., 2014), em um Neossolo Regolítico (Embrapa, 2006).

Foram analisadas área de mata nativa (MN) adjacente a áreas de pastagem de azevém+tifton, com uso de dejetos suínos há dois anos (A2) e 14 anos (A14). As áreas A2 e A14 receberam, no processo de implantação das pastagens, $2 \mathrm{Mg} \mathrm{ha}^{-1}$ de calcário; e são manejadas em sistema de pastejo rotativo com vacas leiteiras e recebem anualmente cerca de $200 \mathrm{~kg} \mathrm{ha}^{-1} \mathrm{ano}^{-1}$ de ureia e $200 \mathrm{~m}^{3} \mathrm{ha}^{-1} \mathrm{ano}^{-1}$ de dejetos. Em cada área, foram realizadas 10 aplicações de dejetos de suínos ao longo de um ano, utilizando-se um distribuidor de esterco líquido, conduzido por um trator. $\mathrm{O}$ delineamento constituiu-se de um fatorial $3 \times 2$, com três áreas e duas épocas de coleta, em três repetições.
A propriedade rural possui uma Unidade de Terminação de suínos, com capacidade para 1.000 animais, os quais, na fase de terminação, produzem em média 9,0 $\mathrm{L} \mathrm{cab}^{-1} \mathrm{dia}^{-1}$ de dejetos líquidos (Dartora et al., 1998). Os suínos são alojados em instalações de alvenaria, que atendem às determinações da empresa integradora, já que o sistema de produção é de integração em parceria. Associada à suinocultura, na propriedade há produção de leite, sendo a pastagem a base da alimentação das vacas leiteiras. No sistema de pastejo rotativo, os animais permanecem, em média, um dia em cada piquete, de onde são retirados para a ordenha.

As coletas para realizar as análises microbiológicas foram feitas em agosto (09/08), no inverno, e novembro (10/11), na primavera, de 2012. Durante os 40 dias que antecederam as coletas, a precipitação pluvial nas áreas analisadas foi monitorada (in loco), e os valores computados foram de 243 e $363 \mathrm{~mm}$ de chuva no inverno e na primavera, respectivamente. As temperaturas médias determinadas nos 30 dias que antecederam as coletas foram de $14,27^{\circ} \mathrm{C}$ para a coleta de agosto e $20,85^{\circ} \mathrm{C}$ para a de novembro, conforme os dados da Estação Meteorológica Automática de Santo Augusto (Inmet, 2015), localizada a cerca de $50 \mathrm{~km}$ do local do estudo (Figura 1).

As análises químicas e físicas foram realizadas apenas na coleta de agosto na camada de 0,00-0,10 m (Quadro 1). Para a caracterização física, foram coletadas, aleatoriamente, três subamostras por repetição coletadas dentro de cada área avaliada, com o uso de anel volumétrico, determinando-se os seguintes atributos: densidade

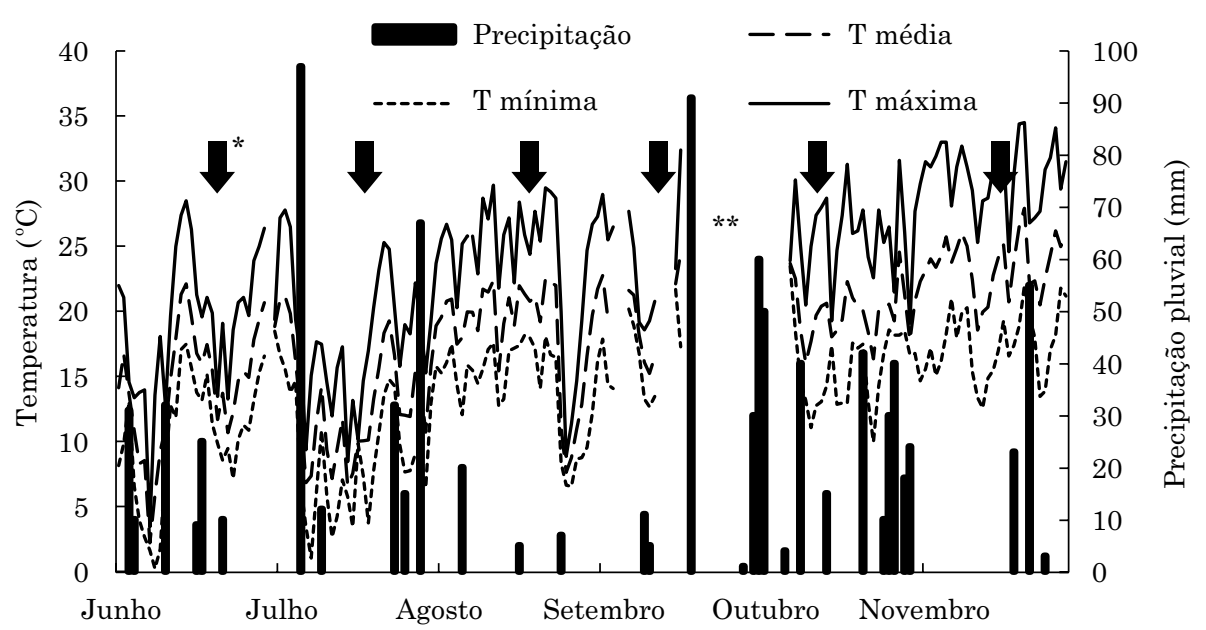

Figura 1. Precipitação pluvial, temperatura média (T média), temperatura mínima (T mínima) e temperatura máxima (T máxima), de Três Passos, RS, referentes ao período de junho a novembro de 2012, obtidas da Estação Meteorológica Automática de Santo Augusto, RS (Inmet, 2015). * As flechas indicam o momento da aplicação dos dejetos líquidos de suínos na área experimental. **Período em que não houve o registro de dados pela Estação Meteorológica. 
do solo (método do anel), microporosidade (mesa de tensão), macroporosidade (porosidade total - microporosidade) e porosidade total (densidade do solo/densidade de partícula) (Embrapa, 1997). Para a caracterização química, foram retiradas, com o uso de trado calador, de forma aleatória, 10 subamostras por repetição para a composição da amostra final, a partir da qual foi realizada a determinação dos seguintes atributos: pH em água (1:1), matéria orgânica (Walkley-Black), K e P (Mehlich-1) e Ca e Mg (KCl $1 \mathrm{~mol} \mathrm{~L}^{-1}$ ) (Tedesco et al., 1995; Embrapa, 1997).

As coletas de solo para as análises microbiológicas foram feitas em agosto (inverno) e em novembro (primavera), na camada de 0,00-0,10 m. Em cada repetição, foram retiradas aleatoriamente 10 subamostras, com um trado calador, para a composição da amostra final. As amostras foram armazenadas em sacos plásticos e transportadas em caixas térmicas com gelo até o laboratório, onde foram peneiradas $(4 \mathrm{~mm})$ e refrigeradas a $4{ }^{\circ} \mathrm{C}$, até se realizarem as análises.

Para determinar o carbono da biomassa microbiana ( $\mathrm{C}$ microbiano) foi utilizado o método de fumigação-extração (Vance et al., 1987; De-Polli

Quadro 1. Características químicas e físicas dos solos das áreas de Mata Nativa (MN), pastagem de azevém+tifton, com uso de dejetos de suínos há dois anos (A2) e há 14 anos (A14), na profundidade de $0,00-0,10 \mathrm{~m}$

\begin{tabular}{|c|c|c|c|}
\hline Atributo & MN & A2 & A14 \\
\hline $\mathrm{pH}\left(\mathrm{H}_{2} \mathrm{O}\right)(1: 1)$ & 6,70 & 5,87 & 5,53 \\
\hline $\mathrm{Ca}^{2+}\left(\mathrm{cmol}_{\mathrm{c}} \mathrm{dm}^{-3}\right)$ & 21,47 & 12,40 & 11,00 \\
\hline $\mathrm{Mg}^{2+}\left(\mathrm{cmol}_{\mathrm{c}} \mathrm{dm}^{-3}\right)$ & 4,23 & 5,90 & 5,13 \\
\hline $\mathrm{H}+\mathrm{Al}\left(\mathrm{cmol}_{\mathrm{c}} \mathrm{dm}^{-3}\right)$ & 1,73 & 3,13 & 5,00 \\
\hline MO (\%) & 6,57 & 3,50 & 6,07 \\
\hline $\mathrm{S}\left(\mathrm{mg} \mathrm{dm}^{-3}\right)$ & 8,87 & 10,53 & 14,33 \\
\hline $\mathrm{P}\left(\mathrm{mg} \mathrm{dm}^{-3}\right)$ & 5,77 & 45,87 & 66,90 \\
\hline $\mathrm{K}\left(\mathrm{mg} \mathrm{dm} \mathrm{m}^{-3}\right)$ & 338,67 & 430,67 & 550,67 \\
\hline $\mathrm{Cu}\left(\mathrm{mg} \mathrm{dm}^{-3}\right)$ & 157,07 & 273,97 & 223,30 \\
\hline $\mathrm{Zn}\left(\mathrm{mg} \mathrm{dm}^{-3}\right)$ & 95,70 & 134,00 & 140,70 \\
\hline Densidade do solo $\left(\mathrm{Mg} \mathrm{m}^{-3}\right)$ & 0,82 & 1,23 & 1,29 \\
\hline Macroporosidade $\left(\mathrm{m}^{3} \mathrm{~m}^{-3}\right)$ & 0,34 & 0,19 & 0,17 \\
\hline Microporosidade $\left(\mathrm{m}^{3} \mathrm{~m}^{-3}\right)$ & 0,31 & 0,43 & 0,42 \\
\hline
\end{tabular}

$\mathrm{Ca}^{2+}$ e $\mathrm{Mg}^{2+}$ : extrator $\mathrm{KCl} 1 \mathrm{~mol} \mathrm{~L}{ }^{-1} ; \mathrm{H}+\mathrm{Al}$ : determinado por acetato de cálcio a pH 7,0; MO: matéria orgânica (método Walkley-Black); S: método turbidimétrico; P, K, Cu e Zn: extrator Mehlich-1 (Tedesco et al., 1995). Densidade do solo: método do anel (Embrapa, 1997); Microporosidade: mesa de tensão (Embrapa, 1997). e Guerra, 1997). Para tal, foram pesados $20 \mathrm{~g}$ de solo, em duplicatas; uma amostra foi fumigada em dessecador acoplado a uma bomba de vácuo contendo um becker com $20 \mathrm{~mL}$ de clorofórmio. Após 24 h, o vapor de clorofórmio foi retirado por meio de evacuações sucessivas. As amostras não fumigadas foram mantidas no escuro. Após a fumigação, as duplicatas foram acondicionadas em frascos de vidro de $200 \mathrm{~mL}$ para o processo de extração do $\mathrm{C}$, sendo adicionado em cada frasco $50 \mathrm{~mL}$ de $\mathrm{K}_{2} \mathrm{SO}_{4} 0,5 \mathrm{~mol} \mathrm{~L}^{-1}$, e o conjunto foi mantido sob agitação $(140 \mathrm{rpm})$ por $30 \mathrm{~min}$. Após esse período, as amostras foram filtradas em papel-filtro $\mathrm{n}^{\circ} 42$, e desse extrato foi retirada uma alíquota de $8 \mathrm{~mL}$ em tubo de ensaio, onde foram adicionados $2 \mathrm{~mL}$ de solução extratora $\left(\mathrm{K}_{2} \mathrm{Cr}_{2} \mathrm{O}_{7} 0,066 \mathrm{~mol} \mathrm{~L}^{-1}\right)$ e $10 \mathrm{~mL}$ de $\mathrm{H}_{2} \mathrm{SO}_{4}$ concentrado. $\mathrm{O}$ conjunto foi então homogeneizado e aquecido em bloco digestor por $30 \mathrm{~min}$ a $150{ }^{\circ} \mathrm{C}$. Após o resfriamento, foram adicionadas três gotas do indicador Ferroin, e o dicromato de potássio em excesso foi titulado com $\left(\mathrm{NH}_{4}\right)_{2} \mathrm{Fe}\left(\mathrm{SO}_{4}\right)_{2} \cdot 6 \mathrm{H}_{2} \mathrm{O} 0,0033 \mathrm{~mol} \mathrm{~L}^{-1}$. Os valores de $\mathrm{C}$ microbiano foram expressos em mg C- $\mathrm{CO}_{2} \mathrm{~kg}^{-1}$.

A respiração microbiana do solo foi estimada pela quantidade de $\mathrm{CO}_{2}$ liberado do solo não fumigado durante 14 dias de incubação (Stotzky, 1972). Utilizaram-se recipientes de vidro de $800 \mathrm{~mL}$ com tampas herméticas, onde uma amostra de $50 \mathrm{~g}$ de solo foi incubada à temperatura ambiente, com a umidade ajustada para $50 \%$ de sua capacidade de campo. Também foram utilizados três recipientes sem solo como controle. $\mathrm{O} \mathrm{CO}_{2}$ produzido foi capturado por $20 \mathrm{~mL}$ de uma solução de $\mathrm{NaOH} 0,5 \mathrm{~mol} \mathrm{~L}^{-1}$ e quantificado por titulação com $\mathrm{HCl} 0,3 \mathrm{~mol} \mathrm{~L}^{-1}$, sendo adicionado anteriormente $3 \mathrm{~mL}$ de $\mathrm{BaCl}_{2} 30 \%$ e utilizado fenolftaleína a $1 \%$ como indicador. Realizaram-se duas titulações após o início da incubação das amostras, sendo a primeira aos sete dias e a segunda aos 14 dias, e os valores foram somados para obter o valor referente ao período de 0 a 14 dias de incubação. Os dados de respiração microbiana foram expressos em $\mathrm{mg} \mathrm{C}-\mathrm{CO}_{2} \mathrm{~kg}^{-1}$.

$\mathrm{O}$ quociente metabólico $\left(q \mathrm{CO}_{2}\right)$ foi obtido dividindo-se a respiração microbiana do solo pelo $\mathrm{C}$ da biomassa microbiana (Balota et al., 2014), e os resultados foram expressos em $\mu \mathrm{g} \mathrm{C}-\mathrm{CO}_{2} \mathrm{~g}^{-1}$.

Determinou-se a atividade da enzima 8 -glicosidase, de acordo com Dick et al. (1996). O substrato usado na reação foi o $p$-nitrofenil-B-D-glucopyranosídeo $0,05 \mathrm{~mol} \mathrm{~L}^{-1}$ (PNG 0,05 mol L-1). As amostras de solo $(1,0 \mathrm{~g})$ foram colocadas em erlenmeyer de $50 \mathrm{~mL}$, sendo utilizado um controle onde só foi adicionado o substrato após a incubação. Em seguida, adicionaram-se $0,25 \mathrm{~mL}$ de tolueno; 4,0 mL da solução MUB pH 6 a todas as amostras; e 1,0 mL de PNG 0,05 mol L-1, com exceção dos controles. Os erlenmeyers foram fechados e incubados a $37^{\circ} \mathrm{C}$, por $1 \mathrm{~h}$. Após a incubação, foram 
adicionados $1,0 \mathrm{~mL}$ de $\mathrm{CaCl}_{2}$ 0,5 $\mathrm{mol} \mathrm{L}^{-1} ; 4,0 \mathrm{~mL}$ de Tris-Hydroxymetyl-Amino-Metano (THAM pH 12); e 1,0 mL de PNG 0,05 $\mathrm{mol} \mathrm{L}^{-1}$ (somente aos controles). Procedeu-se em seguida a filtragem em papel-filtro $\mathrm{n}^{0} 2$. A intensidade da coloração amarela do filtrado foi determinada num espectrofotômetro a $410 \mathrm{~nm}$. A quantidade de $p$-nitrofenol formada em cada amostra foi determinada com base numa curva-padrão preparada com concentrações conhecidas de $p$-nitrofenol $(0,10,20,30,40,50 \mathrm{mg}$ de $p$-nitrofenol $\left.\mathrm{mL}^{-1}\right)$. A atividade enzimática é expressa em mg $p$-nitrofenol $\mathrm{kg}^{-1} \mathrm{~h}^{-1}$.

A atividade da enzima urease foi determinada, segundo Dick et al. (1996). O substrato utilizado na reação da enzima urease foi uma solução de ureia $0,2 \mathrm{~mol} \mathrm{~L}^{-1}$. As amostras $(5,0 \mathrm{~g})$ foram colocadas em tubos de $50 \mathrm{~mL}$, utilizando um controle onde só foi adicionado o substrato após a incubação. Em seguida, foram adicionados $9,0 \mathrm{~mL}$ da solução THAM pH 9,0 em todos os frascos e 1,0 mL da solução de ureia $0,2 \mathrm{~mol} \mathrm{~L}^{-1}$, com exceção dos controles. Os frascos foram fechados e incubados a $37^{\circ} \mathrm{C}$ por $2 \mathrm{~h}$. Após a incubação, foram adicionados aproximadamente $35 \mathrm{~mL}$ de solução refrigerada de $\mathrm{KCl}-\mathrm{Ag}_{2} \mathrm{SO}_{4}$ e $1,0 \mathrm{~mL}$ de solução de ureia $0,2 \mathrm{~mol} \mathrm{~L}^{-1}$, somente aos controles, misturando por alguns segundos. Posteriormente, o conteúdo foi ajustado para $50 \mathrm{~mL}$ com adição de $\mathrm{KCl}-\mathrm{Ag}_{2} \mathrm{SO}_{4}$, e os frascos foram invertidos por diversas vezes para misturar o conteúdo. Para se determinar o N-NH $\mathrm{NH}_{4}^{+}$na suspensão de solo resultante, foi pipetada uma alíquota de $20 \mathrm{~mL}$ da suspensão para um frasco de destilação de $100 \mathrm{~mL}$, e procedeu-se à destilação a vapor dessa alíquota com 0,2 g de $\mathrm{MgO}$ por $4 \mathrm{~min}$, como descrito por Tedesco et al. (1995), para análise do $\mathrm{N}_{-} \mathrm{NH}_{4}^{+}$ do solo. A atividade enzimática foi expressa em $\mu \mathrm{g} \mathrm{N}-\mathrm{NH}_{4}^{+} \mathrm{g}^{-1} 2 \mathrm{~h}^{-1}$.

A hidrólise do diacetato de fluoresceína (FDA) foi determinada pelo método de Green et al. (2006), com algumas alterações descritas na sequência. Foram incubadas, em triplicatas, amostras de $1 \mathrm{~g}$ de solo com $20 \mathrm{~mL}$ de tampão fosfato de sódio $60 \mathrm{mmol} \mathrm{L}^{-1} \mathrm{a}$ $25^{\circ} \mathrm{C}$ durante $15 \mathrm{~min}$ sob agitação a $100 \mathrm{rpm}$. Após esse período, adicionaram-se $100 \mu \mathrm{L}$ da solução de FDA 4,8 $\mathrm{mmol} \mathrm{L}^{-1}$. As amostras foram então agitadas por mais $1 \mathrm{~h} 45 \mathrm{~min}\left(100 \mathrm{rpm}, 25^{\circ} \mathrm{C}\right)$, e, após, foram adicionados $20 \mathrm{~mL}$ de acetona em cada frasco e solução de FDA $4,8 \mathrm{mmol} \mathrm{L}^{-1}$ nas amostras controle, que não receberam essa solução antes da incubação. As amostras foram então centrifugadas a $6.000 \mathrm{rpm}$ por $5 \mathrm{~min}$ e filtradas em papel-filtro $\mathrm{n}^{\circ} 4$. Foi medida a intensidade da cor amarela, em espectrofotômetro a $490 \mathrm{~nm}$; calculou-se a concentração de fluoresceína com o auxílio de uma curva-padrão. A atividade enzimática foi expressa em mg fluoresceína $\mathrm{kg}^{-1} \mathrm{~h}^{-1}$.

Os resultados foram submetidos à análise da variância, e compararam-se as médias pelo teste de Tukey $(\mathrm{p}<0,05)$, com auxílio do software GENES (Cruz, 2006).

\section{RESULTADOS E DISCUSSÃO}

Os valores médios de $\mathrm{C}$ da biomassa microbiana (C microbiano) variaram de 37,3 a 92,8 $\mathrm{mg} \mathrm{C}^{-\mathrm{CO}_{2}} \mathrm{~kg}^{-1}$ (Figura 2a) e, embora esses sejam menores do que os normalmente registrados na literatura (Gatiboni et al., 2011; Kheyrodin et al., 2012; Balota et al., 2014), estão de acordo com os mencionados em estudos no Brasil (Lopes et al., 2010; Couto et al., 2013). $\mathrm{Na}$ análise do $\mathrm{C}$ microbiano para o solo coletado, não foram registradas diferenças significativas entre as áreas estudadas, dentro de cada época de coleta (agosto e novembro) (Figura 2a). Na coleta de agosto, os resultados demonstraram que não houve efeito da adição de dejetos nas áreas analisadas, com valores de C microbiano semelhantes para ambas as áreas analisadas. Na coleta de novembro, a área A14 apresentou valores maiores de $\mathrm{C}$ microbiano em relação à A2.

Esses resultados estão de acordo com as informações da literatura, pois os teores de C microbiano podem apresentar efeito positivo resultante da adição de dejetos de suínos (Balota et al., 2014) ou não (Kheyrodin et al., 2012; Couto et al., 2013), sendo esse resultado dependente da época (Carvalho et al., 2012; Couto et al., 2013) e da profundidade de coleta (Kheyrodin et al., 2012).

A aplicação de dejetos de suínos apresenta efeito positivo significativo na biomassa microbiana, com incremento linear no $\mathrm{C}$ da biomassa de acordo com o aumento da quantidade aplicada (Balota et al., 2012). De modo geral, a inter-relação entre diferentes tipos de manejo, tipos de solo e características próprias de cada solo pode favorecer ou reduzir a atividade microbiana do solo, dependendo da condição ambiental e da inter-relação dos fatores no ambiente (Schmidt et al., 2013).

Embora não tenham ocorrido diferenças significativas entre as áreas, a MN apresentou o maior valor absoluto para o C microbiano nas duas épocas de coleta (Figura 2a). Esses resultados corroboram a informação de que a introdução de práticas agrícolas em ecossistemas naturais normalmente reduz o $\mathrm{C}$ da biomassa (Kaschuk et al., 2011), além de esse ser influenciado por fatores como umidade do solo e aeração (Moreira e Siqueira, 2006), normalmente maiores nos solos de mata nativa, em relação aos solos manejados.

Nas áreas MN e A2, no entanto, foram encontradas diferenças significativas entre as épocas de coleta, com os maiores teores registrados na coleta realizada durante o inverno (agosto) (Figura 2a). Isso pode 
(1)

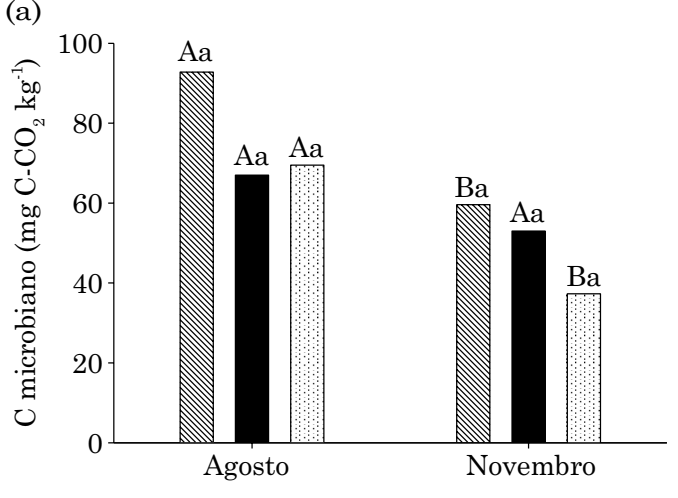

(b)

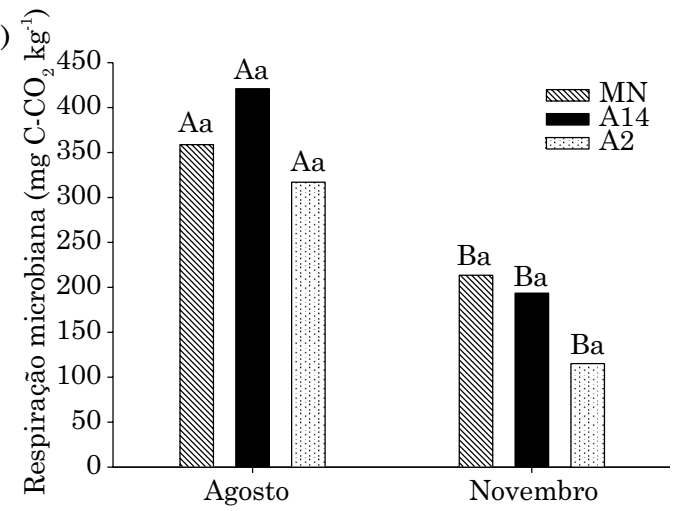

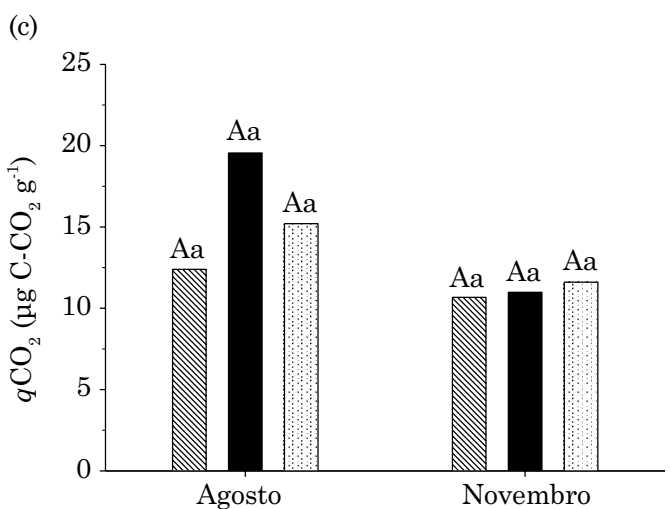

Figura 2. Carbono microbiano (a), respiração microbiana acumulada em 14 dias (b) e quociente metabólico $\left(q \mathrm{CO}_{2}\right)(c)$ em amostras de solo das áreas MN (Mata Nativa), A2 (pastagem de azevém+tifton, com uso de dejetos suínos há dois anos) e A14 (pastagem de azevém+tifton, com uso de dejetos suínos há 14 anos), em duas épocas de coleta (agosto e novembro). Médias seguidas pela mesma letra minúscula, entre tratamentos, e maiúscula, entre épocas, não diferem estatisticamente entre si pelo teste de Tukey a $5 \%$.

ser explicado pelo fato de esse período estar menos sujeito às variações bruscas de temperatura no solo, que podem influenciar negativamente o $\mathrm{C}$ microbiano, além da importância da cobertura vegetal (Carvalho et al., 2012) e do tipo de cobertura (Gatiboni et al., 2011) presente na área na época das coletas. Em agosto, a cultura do azevém se apresentava em pleno desenvolvimento, enquanto que, em novembro, estava em franco processo de decadência, contribuindo para a redução dos valores do $\mathrm{C}$ microbiano nesse período. A tifton, por sua vez, estava em processo de rebrote na coleta de agosto (inverno) e praticamente estabelecida na de novembro (primavera). Ao avaliaram o efeito sucessional (diferentes idades) do pínus chinês e das estações nas propriedades microbiológicas do solo, Yuan e Yue (2012) verificaram efeito significativo das estações no C microbiano; entretanto, os maiores valores foram encontrados no outono; e os menores, no inverno.

Em relação à respiração microbiana do solo, não foram registradas diferenças significativas entre as áreas estudadas (Figura 2b). Mesmo assim, os resultados demonstraram que em ambas as épocas de coleta a área A14 apresentou maiores valores de respiração em relação à $\mathrm{A} 2$; na coleta de agosto, os valores foram maiores, inclusive, em relação à área MN. Na análise de áreas de pastagem em Santa Catarina, sul do Brasil, Couto et al. (2013) também não encontraram diferenças entre a testemunha e as diferentes doses de dejetos de suínos, aplicadas em superfície e em profundidade no solo, em quatro das sete épocas do estudo. A respiração microbiana foi significativamente maior quando se utilizaram duas vezes a dose máxima recomendada de dejeto líquido de suínos (equivalente a $180 \mathrm{~kg} \mathrm{ha}^{-1} \mathrm{~N}$ ) em três das sete épocas analisadas. Nesses casos, de acordo com os autores, a aplicação de altos níveis de $\mathrm{C}$ lábil e a baixa relação $\mathrm{C}: \mathrm{N}$ do dejeto estimularam a comunidade microbiana do solo. A respiração microbiana indica a atividade biológica e decomposição dos resíduos orgânicos do solo (Lopes et al., 2010), de modo que os resultados similares entre as áreas, ou a ausência de diferenças 
significativas, evidenciam que a atividade biológica do solo não foi influenciada pela adição de dejetos líquidos de suínos. $\mathrm{Na}$ segunda época de coleta, a maior respiração microbiana foi registrada para a área MN, sendo normal as áreas de vegetação nativa apresentarem respiração microbiana acima das demais (Lopes et al., 2010), e para a área A14, em relação à A2 (Figura $2 \mathrm{~b})$. Esse comportamento da área A14 ocorreu, provavelmente, em resposta à maior adição de matéria orgânica. Entretanto, não foram registradas diferenças significativas entre as áreas analisadas. Considerando que taxas muito elevadas de respiração microbiana podem indicar a possibilidade de maiores perdas de $\mathrm{C}$ do solo, como consequência de degradação mais acelerada, a similaridade entre as áreas permite inferir que a adição dos dejetos líquidos de suínos não implica em maiores perdas de $\mathrm{C}$ do solo, sendo capaz de manter o nível de atividade biológica do solo semelhante aos de áreas de mata nativa (área MN).

Entretanto, foram registradas diferenças significativas na respiração microbiana entre as épocas (agosto e novembro) para todas as áreas analisadas, com a ocorrência dos maiores valores na coleta realizada em agosto (Figura 2b). Esse resultado provavelmente está relacionado às condições climáticas favoráveis em termos de temperatura e precipitação à comunidade microbiana durante o período de inverno (agosto) e desfavoráveis na primavera (novembro) em razão do excesso de precipitação pluvial, já que ocorreram mais de $360 \mathrm{~mm}$ de chuva nos 40 dias que antecederam a coleta do período. Essa umidade excessiva pode ter influenciado negativamente a comunidade microbiana durante a primavera, refletindo nos menores valores gerais em relação à coleta do inverno (agosto). A estação de amostragem também influenciou os valores de $\mathrm{C}$ microbiano $\mathrm{e}$ atividade microbiana em trabalho realizado por Carvalho et al. (2012). Efeito das estações nas propriedades microbiológicas do solo foi observado por Yuan e Yue (2012), em estudo com pínus chinês, os quais obtiveram maiores valores de respiração microbiana no verão, e menores, no inverno.

Considerando que o uso sucessivo de dejetos de suínos nos solos em estudo não influenciou significativamente o $\mathrm{C}$ microbiano e a respiração microbiana, pode-se inferir que essa prática de manejo do solo permite a manutenção dos níveis de qualidade do solo.

$\mathrm{O}$ quociente metabólico $\left(q \mathrm{CO}_{2}\right)$ representa a quantidade de $\mathrm{Cliberada}$ na forma de $\mathrm{CO}_{2}$ por unidade de biomassa microbiana em determinado tempo (Couto et al., 2013). Em ambas as épocas de coleta, a área $\mathrm{MN}$ apresentou o menor $q \mathrm{CO}_{2}$, evidenciando, portanto, os mais eficientes índices de uso do $\mathrm{C}$ pela biomassa microbiana (Figura 2c). Entretanto, não foram registradas diferenças significativas para 0 $q \mathrm{CO}_{2}$ entre as áreas estudadas. Em termos gerais, os valores médios encontrados variaram de 10,67 $\mu \mathrm{g} \mathrm{C}-\mathrm{CO}_{2} \mathrm{~g}^{-1}$, para área $\mathrm{MN}$ na coleta de novembro, até $19,55 \mu \mathrm{g}$ C- $\mathrm{CO}_{2} \mathrm{~g}^{-1}$, para a área A14 na coleta de agosto, corroborando os valores médios citados por Couto et al. (2013), de 18,7 $\mu \mathrm{g}$ C- $\mathrm{CO}_{2} \mathrm{~g}^{-1}$, na análise do efeito de diferentes doses de dejetos de suínos no solo.

Em agosto, a área A14 apresentou os maiores valores de $q \mathrm{CO}_{2}$, sem diferenças significativas com as demais áreas (Figura 2c). Em novembro, todas as áreas demonstraram valores menores em relação à coleta de agosto, provavelmente em razão da ocorrência de precipitação pluvial em excesso no período que antecedeu essa coleta. Entretanto, para esse período, os valores registrados foram todos muito próximos entre si e, considerando-se que na coleta de agosto não foram registradas diferenças entre as áreas estudadas, é provável que a comunidade microbiana esteja estabilizada, com o uso do C pela biomassa microbiana igualmente distribuído entre as áreas analisadas.

As enzimas são importantes componentes envolvidos nas dinâmicas transformações dos nutrientes do solo ( $\mathrm{Hu}$ et al., 2014), tendo participação fundamental nos processos relacionados às qualidades física, química e biológica do solo (Moreira e Siqueira, 2006). Na análise enzimática do solo, não foram registradas diferenças significativas entre as áreas estudadas nos valores da B-glicosidase (Figura 3a).

Entretanto, em ambas as épocas, a atividade enzimática foi maior nas áreas com adição de dejetos, como resposta favorável dessa enzima à adubação orgânica do solo (Figura 3a) (Moreira e Siqueira, 2006). Analisando a influência do pastejo na atividade biológica do solo, Prieto et al. (2011) registraram declínio na atividade da B-glicosidase em reposta à redução da cobertura vegetal das gramíneas perenes estudadas, em razão do pastejo. Nesse estudo, entretanto, é possível que o pastejo não tenha ocasionado a redução da cobertura vegetal em nível capaz de influenciar a atividade da enzima em questão, mantendo-se todas as áreas no mesmo padrão de atividade e sem apresentar resposta ao uso de dejetos de suínos no solo.

No estudo de indicadores de conservação e interferência antrópica em florestas de araucária, Carvalho et al. (2012) verificaram que essa enzima também não apresentou diferenças significativas entre as áreas de estudo e nem entre as épocas analisadas. A B-glicosidase foi sensível na diferenciação entre os sistemas de plantio, sendo menor no plantio convencional em relação ao sistema de plantio direto em trabalho conduzido por Lisboa et al. (2012). Com base nos resultados, embora essa enzima possa ser utilizada em outros estudos com outros objetivos, é possível inferir que a B-glicosidase não é um bom indicador de qualidade do solo para 

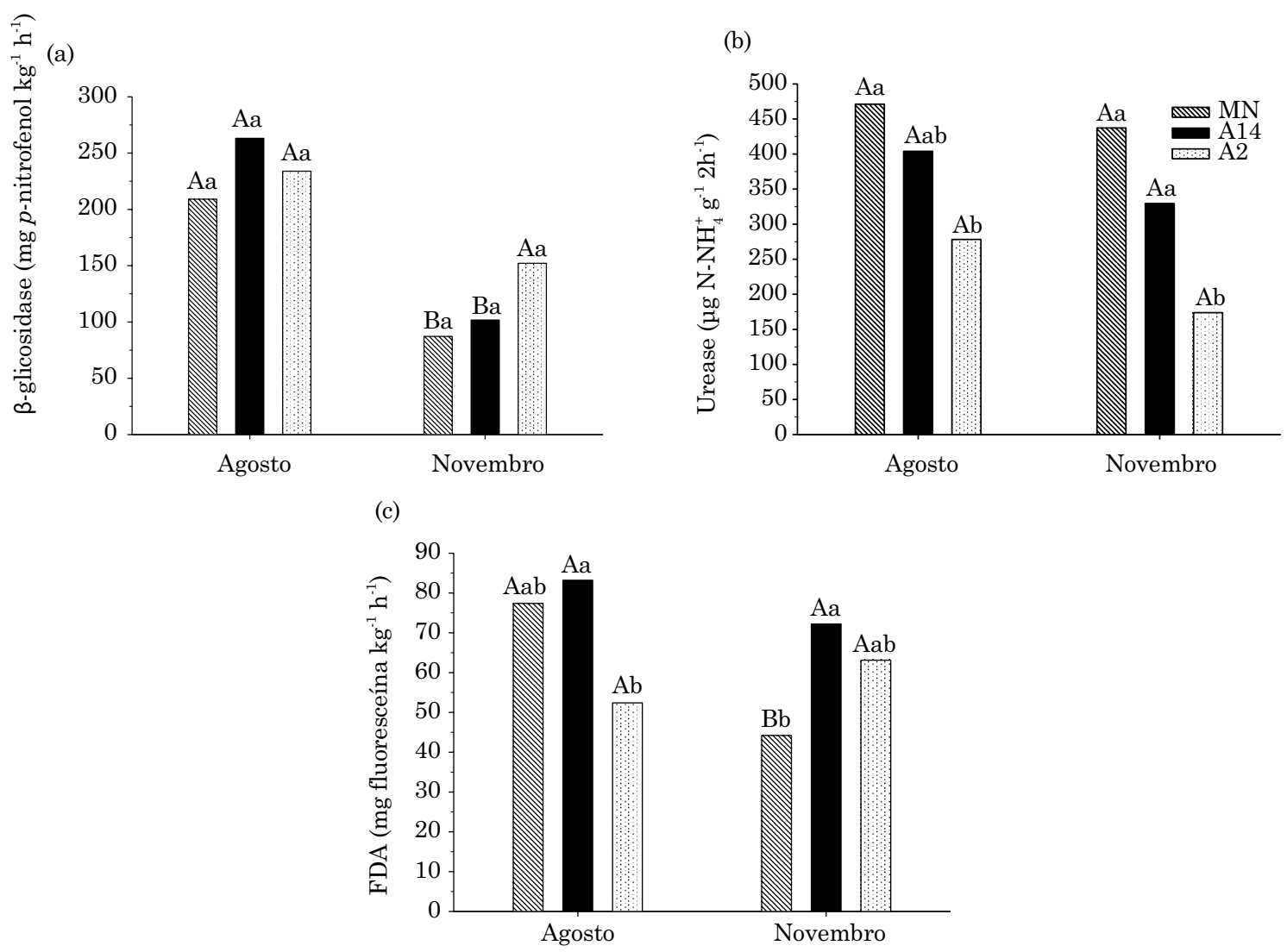

Figura 3. Valores da $\beta$-glicosidase (a), da urease (b) e da hidrólise do diacetato de fluoresceína (FDA) (c) em amostras de solo das áreas MN (Mata Nativa), A2 (pastagem de azevém+tifton, com uso de dejetos suínos há dois anos) e A14 (pastagem de azevém+tifton, com uso de dejetos suínos há 14 anos), em duas épocas de coleta (agosto e novembro). Médias seguidas pela mesma letra minúscula, entre tratamentos, e maiúscula, entre épocas, não diferem estatisticamente entre si pelo teste de Tukey a $5 \%$.

o estudo de áreas com uso sucessivo de dejetos de suínos, tendo como parâmetro a área de mata nativa.

A enzima urease libera $\mathrm{N}-\mathrm{NH}_{4}^{+}$, por meio da hidrólise da ureia, essenciais na cadeia dos amino componentes (Hu et al., 2014). Neste estudo, a urease apresentou diferenças significativas entre as áreas analisadas (Figura 3b). Em ambas as épocas de coleta (agosto e novembro), as áreas MN e A14, que receberam dejetos de suínos há mais tempo, evidenciaram as maiores atividades dessa enzima. $\mathrm{Na}$ coleta de agosto, na área MN, a atividade da urease foi significativamente maior do que na área A2, não diferindo da área A14. A atividade da urease, em geral, também foi maior nos solos sob vegetação nativa (campo nativo - $\mathrm{CN}$ ) e em sistema de plantio direto (PD), como constatado por Lisboa et al. (2012), os quais atribuíram esse comportamento aos maiores teores de matéria orgânica no PD em relação ao plantio convencional (PC) e à similaridade das áreas de PD com as áreas de $\mathrm{CN}$.

Em novembro, as áreas MN e A14 diferiram da A2, com a atividade da urease sendo significativamente maior (Figura 3b). Esse resultado corrobora o do estudo realizado por $\mathrm{Hu}$ et al. (2014), em que a atividade enzimática foi influenciada pelo uso sucessivo de esterco e fertilização química do solo, sendo a maior atividade da urease registrada nos tratamentos que receberam adubação com esterco. $\mathrm{O}$ uso de diferentes doses de dejetos líquidos de suínos e o preparo do solo também influenciaram a atividade enzimática do solo, que apresentou diferentes tendências de acordo com a enzima (celulase, arilsufatase e fosfatase ácida), as diferentes doses de dejetos utilizadas e o manejo e a profundidade do solo estudada, de modo que a atividade das enzimas do solo foi considerada uma medida sensível capaz de detectar mudanças no solo em razão da aplicação de dejetos de suínos (Balota et al., 2011). A urease também demonstrou ser uma das enzimas mais sensíveis na análise de indicadores de qualidade do solo no Paraná, promovendo os mais distintos níveis entre diferentes usos do solo (Kuwano et al., 2014).

A urease também apresentou diferenças entre os níveis de interferência antrópica em áreas de araucária, sem entretanto evidenciar diferenças entre as épocas de coleta (Carvalho et al., 2012), assim como neste estudo, em que também não foram 
registradas diferenças para a atividade da urease entre as épocas de coleta (Figura 3 b). A atividade da urease foi significativamente maior com a adição de dejetos líquidos de suínos nos tratamentos sem revolvimento do solo, como constatado por Kheyrodin et al. (2012).

A atividade enzimática da hidrólise do diacetato de fluoresceína (FDA) apresentou diferenças significativas entre as áreas e entre as épocas estudadas (Figura 3c). Em ambas as épocas, os maiores valores foram registrados para a área A14, que recebeu adição sucessiva de dejetos de suínos há mais tempo, com diferença significativa para a área A2 na primeira época de coleta (agosto) e da área MN na segunda época (novembro). Esse comportamento deve ter ocorrido em resposta à degradação que ocorre primeiro nos materiais orgânicos recentemente adicionados ao solo, ou parte deles, que contêm uma fonte mais lábil de nutrientes, assim como os dejetos de suínos (Couto et al., 2013). Os valores da hidrólise de FDA foram maiores nas áreas de floresta nativa e nas áreas com Panicum maximum Jacq., que Lopes et al. (2010) atribuíram à maior deposição de resíduos, já que a enzima participa ativamente nas transformações da matéria orgânica do solo. A atividade microbiana, mediada pela hidrólise de FDA, foi semelhante entre as áreas de pastejo analisadas, em sistema de integração lavoura-pecuária; entretanto, menor do que na área não pastejada (Chávez et al., 2011).

Entre as épocas de coleta, houve diferença significativa para a área $\mathrm{MN}$ com a maior atividade da FDA registrada para a coleta de agosto (Figura 3c). Esse resultado provavelmente está relacionado às condições de excesso de precipitação pluvial registrado nos 40 dias que antecederam a coleta de novembro, prejudicial às comunidades microbianas. Diferenças significativas na hidrólise de FDA não foram encontradas por Carvalho et al. (2012) entre os tratamentos aplicados e nem entre as estações analisadas. De maneira geral, o uso de dejetos de suínos em pastagem influencia o comportamento dos bioindicadores de qualidade do solo, dependendo da época de coleta. Esse comportamento é também dependente do bioindicador em questão, já que o $\mathrm{C}$ microbiano, a respiração microbiana e o quociente metabólico não foram influenciados pelo uso de dejetos, e a atividade enzimática foi influenciada de forma diferenciada de acordo com a enzima estudada e a época de coleta do solo.

A adubação com dejetos de animais é importante para a manutenção da matéria orgânica e promoção da atividade biológica do solo, que resulta em substancial incremento da produtividade e pode ser sustentável por muitos anos (Hu et al., 2014). $\mathrm{O}$ material orgânico adicionado na superfície do solo contribui tanto para o acúmulo de $\mathrm{C}$ quanto para a maior atividade microbiana do solo, já que atua como substrato no processo de decomposição, colaborando, sobremaneira, para a manutenção do sistema produtivo, por meio do aumento da liberação de nutrientes para o desenvolvimento vegetal (Janzen, 2006). Sendo assim, é essencial que se busque melhor compreensão dos fluxos de $\mathrm{C}$ no solo para encontrar o ponto de equilíbrio nas condições do ecossistema em estudo (Janzen, 2006), contribuindo para otimizar as atividades agropecuárias desenvolvidas com o uso de dejetos líquidos de suínos no solo.

\section{CONCLUSÕES}

O uso sucessivo de dejetos de suínos em pastagem não influenciou o carbono da biomassa e a respiração microbiana, que variaram conforme a época de coleta.

O quociente metabólico não foi influenciado pelo uso de dejetos de suínos no solo.

A atividade enzimática do solo foi motivada pelo uso de dejetos de suínos, sendo o comportamento dependente da enzima analisada e da época de amostragem.

A urease e a hidrólise do diacetato de fluoresceína (FDA) são sensíveis na detecção de diferenças na atividade dos solos com uso de dejetos de suínos.

A enzima B-glicosidase não permite a diferenciação entre as áreas com mata nativa adjacente às áreas de pastagem com uso de dejetos suínos há dois anos e 14 anos.

\section{REFERÊNCIAS}

Araújo EA, Ker JC, Neves JCL, Lani JL. Qualidade do solo: conceitos, indicadores e avaliação. Pesq Aplic Agrotecnol. 2012;5:187-206.

Balota EL, Machineski O, Hamid KIA, Yada IFU, Barbosa GMC, Nakatani AS, Coyne MS. Soil microbial properties after long-term swine slurry application to conventional and no-tillage systems in Brazil. Sci Total Environ. 2014;490:397-404.

Balota EL, Machineski O, Matos MA. Soil microbial biomass under different tillage and levels of applied pig slurry. $\mathrm{R}$ Bras Eng Agríc Amb. 2012;16:487-95.

Balota EL, Machineski O, Truber PV. Soil enzyme activities under pig slurry addition and different tillage system. Acta Sci Agron. 2011;33:729-37.

Basso CJ, Ceretta CA, Flores EMM, Girotto E. Teores totais de metais pesados no solo após aplicação de dejeto líquido de suínos. Ci Rural. 2012;42:653-9. 
Carvalho F, Moreira FMS, Cardoso EJBN. Chemical and biochemical properties of Araucaria angustifolia (Bert.) Ktze. forest soils in the State of São Paulo. R Bras Ci Solo. 2012;36:1189-201.

Chávez LF, Escobar LF, Anghinoni I, Carvalho PCF, Meurer EJ. Diversidade metabólica e atividade microbiana no solo em sistema de integração lavoura-pecuária sob intensidade de pastejo. Pesq Agropec Bras. 2011;46:1254-61.

Couto RR, Comin JJ, Soares CRFS, Belli Filho P, Benedet L, Moraes MP, Brunetto G, Beber CL. Microbiological and chemical attributes of a Hapludalf soil with swine manure fertilization. Pesq Agropec Bras. 2013;48:774-82.

Cruz CD. Programa GENES: Biometria. Viçosa, MG: Universidade Federal de Viçosa; 2006.

Dartora V, Perdomo CC, Tumelero IT. Manejo de dejetos suínos. Concórdia: Embrapa/CNPSA/Emater/RS; 1998.

De-Polli H, Guerra JGM. Determinação do carbono da biomassa microbiana do solo: método da fumigação-extração. Seropédica: Embrapa/Cnpab; 1997. (Documentos, 37).

Dick RP, Breackwell DP, Turco RF. Soil enzyme activities and biodiversity measurements as integrative microbiological indicators. In: Doran JW, Jones AJ, editors. Methods for assessing soil quality. Madison: Soil Science Society of America; 1996. p.247-71.

Empresa Brasileira de Pesquisa Agropecuária - Embrapa. Centro Nacional de Pesquisa do Solo. Manual de métodos de análise do solo. $2^{\mathrm{a}}$.ed. Rio de Janeiro: 1997.

Empresa Brasileira de Pesquisa Agropecuária - Embrapa. Sistema brasileiro de classificação de solos. $3^{\text {a }}$.ed. Rio de Janeiro: 2006.

Gatiboni LC, Coimbra JLM, Denardin RBN, Wildner LP. Microbial biomass and soil fauna during the decomposition of cover crops in no-tillage system. R Bras Ci Solo. 2011;35:1151-7.

Giacomini DA, Aita C, Pujol SB, Giacomini SJ, Doneda A, Cantú RR, Dessbesell A, Lüdtke RC, Silveira CAP. Mitigação das emissões de amônia por zeólitas naturais durante a compostagem de dejetos de suínos. Pesq Agropec Bras. 2014;49:521-30.

Girotto E, Ceretta CA, Brunetto G, Rheinheimer DS, Silva LS, Lourenzi CR, Lorensini F, Vieira RCB, Schmatz R. Acúmulo e formas de cobre e zinco no solo após aplicações sucessivas de dejeto líquido de suínos. R Bras Ci Solo. 2010;34:955-65.

Green VS, Stott DE, Miack M. Assay for fluorescein diacetate hydrolytic activity: optimization for soil samples. Soil Biol Biochem. 2006;38:693-701.

Hernández D, Polo A, Plaza C. Long-term effects of pig slurry on barley yield and $\mathrm{N}$ use efficiency under semiarid Mediterranean conditions. Eur J Agron. 2013;44:78-86.

Hu W, Jiao Z, Wu F, Liu Y, Dong M, Ma X, Fan T, An L, Feng H. Long-term effects of fertilizer on soil enzymatic activity of wheat field soil in Loess Plateau, China. Ecotoxicology. 2014;23:2069-80.

Instituto Nacional de Meteorologia - Inmet. Dados Históricos - BDMEP - Banco de Dados Meteorológicos para Ensino e Pesquisa. [Acessado em: 27 abr. 2015]. Disponível em: http:// www.inmet.gov.br/portal/index.php?r=home/page\&page=rede_ estacoes_auto_graf.

Janzen HH. The soil carbon dilemma: shall we hoard at or use it? Soil Biol Biochem. 2006;38:419-24.

Kaschuk G, Alberton O, Hungria M. Quantifying effects of different agricultural land uses on soil microbial biomass and activity in Brazilian biomes: inferences to improve soil quality. Plant Soil. 2011;338:467-81.

Kheyrodin H, Ghazvinian K, Taherian M. Tillage and manure effect on soil microbial biomass and respiration, and on enzyme activities. Afr J Biotechnol. 2012;11:14652-9.

Kuwano BH, Knob A, Fagotti DSL, Melém Júnior NJ, Godoy L, Diehl RC, Krawulski CC, Andrade Filho G, Zangaro Filho W, Tavares-Filho J, Nogueira MA. Soil quality indicators in a Rhodic Kandiudult under different uses in northern Parana, Brazil. R Bras Ci Solo. 2014;38:50-9.

Lisboa BB, Vargas LK, Silveira AO, Martins AF, Selbach PA. Indicadores microbianos de qualidade do solo em diferentes sistemas de manejo. R Bras Ci Solo. 2012;36:45-55.

Lopes MM, Salviano AAC, Araújo ASF, Nunes LAPL, Oliveira ME. Changes in soil microbial biomass and activity in different Brazilian pastures. Spanish J Agric Res. 2010;8:1253-9.

Moreira FMS, Siqueira JO. Microbiologia e bioquímica do solo. $2^{a}$.ed. Lavras: Universidade Federal de Lavras; 2006.

Prieto LH, Bertiller MB, Carrera AL, Olivera NL. Soil enzyme and microbial activities in a grazing ecosystem of Patagonian Monte, Argentina. Geoderma. 2011;162:281-7.

Sá MF, Aita C, Doneda A, Pujol SB, Cantú RR, Jacques IVC, Bastiani GG, Oliveira PD, Lopes PD. Dinâmica da população de coliformes durante a compostagem automatizada de dejetos líquidos de suínos. Arq Bras Med Vet Zootec. 2014;66:1197-206.

Scherer EE, Nesi CN, Massotti Z. Atributos químicos do solo influenciados por sucessivas aplicações de dejetos suínos em áreas agrícolas de Santa Catarina. R Bras Ci Solo. 2010;34:1375-83.

Schmidt RO, Sana RS, Leal FK, Andreazza R, Camargo FAO, Meurer EJ. Biomassa e atividade microbiana do solo em sistemas de produção olerícola orgânica e convencional. Ci Rural. 2013;43:270-6.

Silva RF, Bertollo GM, Corassa GM, Cocco LB, Steffen RB, Basso CJ. Doses de dejeto líquido de suínos na comunidade da fauna edáfica em sistema plantio direto e cultivo mínimo. Ci Rural. 2014;44:418-24.

Stotzky G. Activity, ecology and population dynamics of soil microorganisms. Crit Rev Microbiol. 1972;2:59-137.

Tedesco JM, Gianello C, Bissani CA, Bohnen H, Wolkweiss SJ. Análise de solo, plantas e outros materiais. $2^{\mathrm{a}}$. ed. Porto Alegre: Universidade Federal do Rio Grande do Sul; 1995.

Vance ED, Brookes PC, Jenkinson DS. An extraction method for measuring soil microbial biomass C. Soil Biol Biochem. 1987;19:703-7.

Yuan BC, Yue DX. Soil microbial and enzymatic activities across a chronosequence of Chinese pine plantation development on the Loess Plateau of China. Pedosphere. 2012;22:1-12. 